\title{
Research on the mechanical behaviour of an airplane component made by selective laser melting technology
}

\author{
Răzvan Păcurar ${ }^{1, *}$, Ancuța Păcurar ${ }^{1}$, and Nicolae Bâlc ${ }^{1}$ \\ ${ }^{1}$ Technical University of Cluj-Napoca, Faculty of Machine Building, Department of Manufacturing \\ Engineering, B-dul Muncii no. 103-105, 400641, Cluj-Napoca, Romania
}

\begin{abstract}
The main objective of the presented research consists in the redesign of an airplane component to decrease its weight, without affecting the mechanical behaviour of the component, at the end. Femap NX Nastran and ANSYS FEA programs were used for the shape optimization and for the estimation of the mechanical behaviour of a fixing clamp that was used to sustain the hydraulic pipes that are passing through an airplane fuselage, taking into consideration two types of raw materials - Ti6Al4V and AlSi12 powder from which this component could be manufactured by using the selective laser melting (SLM) technology. Based on the obtained results, the airplane component was finally manufactured from titanium alloy using the SLM $250 \mathrm{HL}$ equipment that is available at SLM Solutions GmbH company from Luebeck, in Germany.
\end{abstract}

\section{Introduction}

Airplane industry is one of the most spectacular fields of research regarding the Selective Laser Melting (SLM) technology. New types of materials were successfully developed in the last years in this field, being machinable on the SLM modern equipment [1-3]. The mechanical behaviour of the airplane components produced from different type of materials was one of the most important researches developed in this field by different researchers in the world [4-5]. Shape optimization and FEA programs are often used in order to estimate the mechanical behaviour of different type of airplane components made by SLM technology [6-9]. The research performed by the authors in this field of research was mainly focused on the possibility of redesigning of an airplane component - the fixing clamp used for sustaining the hydraulic pipes that are passing through an airplane fuselage, in such way that the weight will be significantly decreased, without affecting the mechanical behaviour of the component, at the end. Femap NX Nastran program was successfully used for optimizing the shape of the component and ANSYS FEA program was successfully used for estimating the stress and strain values of the component to be made by aluminium or titanium alloy by SLM. Based on the obtained results, the fixing clamp was manufactured from Ti6Al4V material by selective laser melting technology at SLM Solutions GmbH company from Luebeck, Germany, at the end.

*Corresponding author: razvan.pacurar@tcm.utcluj.ro 


\section{Redesign of an airplane component made by SLM technology}

The research performed in the field of aerospace industry was focused on the redesigning and analysis of the airplane component presented in Fig. 1.a), with the aim of decreasing the weight of the component without affecting its mechanical strength at the end. For the redesigning process of the airplane component, a dedicated topology optimization program called Femap NX Nastran was used, knowing that in the bore area of the component (Ø50 $[\mathrm{mm}]$ - size diameter), a force will be applied on the entire circumference and knowing that the base area of the component will be fixed with 8 screws on the airplane fuselage. These were the main constrains that were applied in the case of the airplane component, as presented in Fig. 1.b).

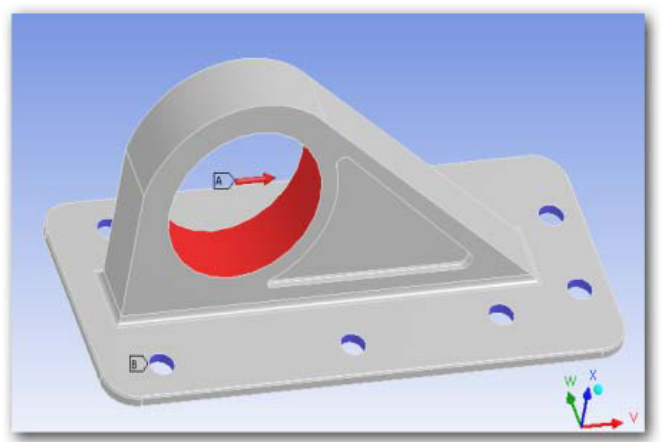

a)

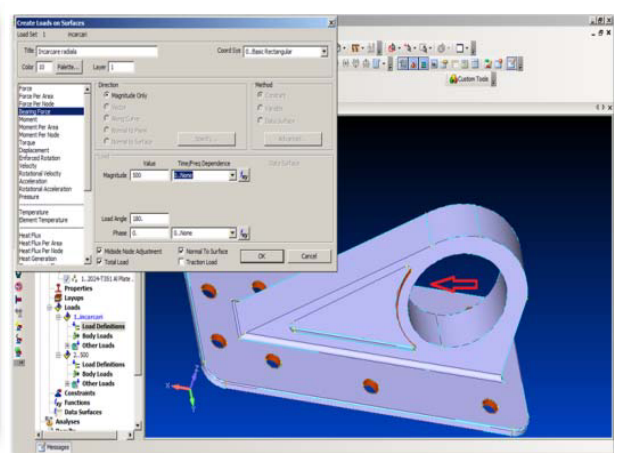

b)

Fig.1. Kinematical and loading constrains applied on the component surface - Femap NX Nastran.

Two types of materials machinable by Selective Laser Melting (SLM) process were considered for the made analysis - TiAl6V4 and AlSi12, the mechanical characteristics, such as Tensile strength, Yield strength or Poisson ratio, undertaken from the material file of the supplier company (SLM Solutions GmbH from Germany) being defined manually in the library of the FEMAP program, as well. After the mesh was generated, by specifying the percent volume reduction in the FEMAP program (variable percent), it was possible to observe that a significant volume of the material can be removed in the connecting area of the base plate and supporting leg of the component (see Fig. 2 a, b and c). Same observation was valid in the case when the TiAl6V4 or AlSi12 material was considered for the manufacturing of the airplane component and with the increasing of loading force from $500[\mathrm{~N}]$ to $3000[\mathrm{~N}]$, range that was considered for the made analysis.

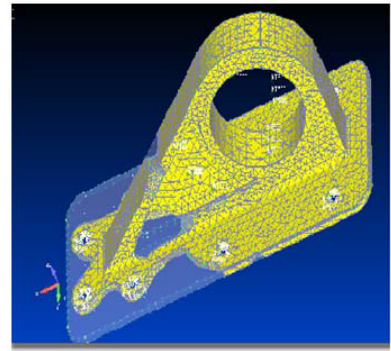

a)

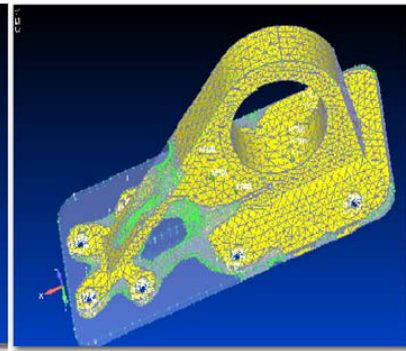

b)

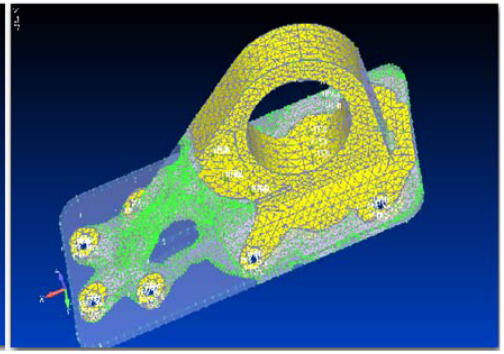

c)

Fig.2. Results of the topology optimization for the percent volume reduction of: a) $20 \%$; b) $30 \%$; c) $45 \%$. 
Based on the results obtained using the Femap NX Nastran program, the optimized shape of the airplane component has been designed using SolidWorks program, as presented in Fig. 3. Further analyses regarding the mechanical behaviour of the fixing clamp were required to be made using the ANSYS FEA program.

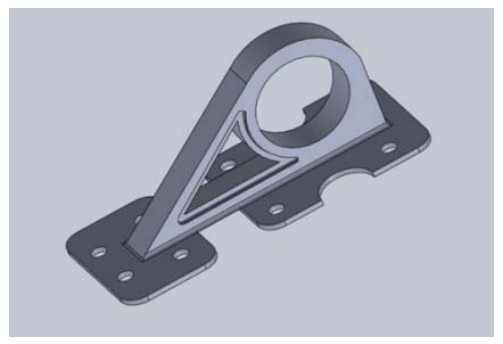

Fig.3. Shape of the fixing clamp after the topology optimization performed by Femap NX Nastran.

\section{Finite element analyses to estimate the mechanical behaviour of the airplane component made by SLM}

For the made analysis performed by ANSYS program, first of all it was necessary to specify the thermal and mechanical characteristics of the material, as shown in Fig. 4.a). Thermal expansion coefficient, Young's modulus, Poisson's ratio and Yield Strength are only few of the characteristics that were defined in the ANSYS material loading window, as they were specified on the material file from the supplier company website (SLM Solutions GmbH from Luebeck, Germany) [10] (see Fig. 4.b).

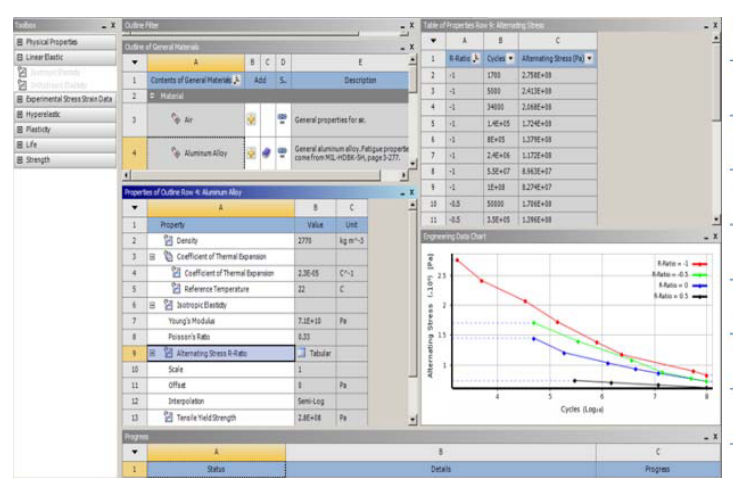

a)

\begin{tabular}{|c|c|c|c|}
\hline $\begin{array}{l}\text { Mechanische Daten } \\
\text { Mechanical Data }\end{array}$ & & TiAl6V4* & AlsI 12 \\
\hline $\begin{array}{l}\text { Zugfestigkeit } \\
\text { Tênsile strength } \\
\end{array}$ & $\mathrm{R}_{\mathrm{m}}[\mathrm{MPa}]$ & $960( \pm 30)$ & $409( \pm 20)$ \\
\hline $\begin{array}{l}\text { Dehngrenze } \\
\text { Offset yield stress }\end{array}$ & $R_{9,2,2}[M P a ̈]$ & $815( \pm 40)$ & $211( \pm 20)$ \\
\hline $\begin{array}{l}\text { Hărtè } \\
\text { Hardness }\end{array}$ & & $37,3 \mathrm{HRC}[ \pm 2]$ & $105 \mathrm{HB}| \pm 1|$ \\
\hline $\begin{array}{l}\text { Bruchdehnung } \\
\text { Breake strain A } \\
\end{array}$ & {$[\%]$} & $10-18$ & 5.1 \\
\hline $\begin{array}{l}\text { Wärmeleitfähigkeit bei } \\
\text { Thermal conductivity at }\end{array}$ & $20^{\circ} \mathrm{C}[\mathrm{W} / \mathrm{mk}]$ & 7.1 & $\cdot$ \\
\hline $\begin{array}{l}\text { Rauigkeit } \\
\text { Surfacè roughñess }\end{array}$ & $\mathrm{R}_{2} \mathrm{XN}[\mu \mathrm{m}]$ & $14 \mid+2]$ & $15| \pm 2|$ \\
\hline $\begin{array}{l}\text { Rauigkeit } \\
\text { Surfaçe roughnesss }\end{array}$ & $\mathrm{R}_{2} Z\lfloor\mu \mathrm{m}]$ & $36| \pm 4|$ & $34( \pm 4)$ \\
\hline
\end{tabular}

b)

Fig.4. Thermal and mechanical characteristics of the materials defined in the ANSYS FEA program.

The next step of the made analyses consisted in the loading of the 3D model in "*.igs" format and the establishment of the kinematical and technological constrains. As shown in Fig. 5. a), the part has been considered fixed in the 8 bores from the base plate area, while a force of $500[\mathrm{~N}]$ has been considered acting on the circumference of the larger bore area, indicated with arrow in this figure. Last step before running the analyses consisted in the mesh generation. A mesh having a total number of 122.037 nods and 77.349 elements was generated as presented in Fig. 5. b). After running the made analyses, both in the case when part has been considered made of TiAl6V4 and AlSi12 materials, some appreciations were made regarding the stress and strain values of the component made of these specific materials (see Fig. 6. a and b). 


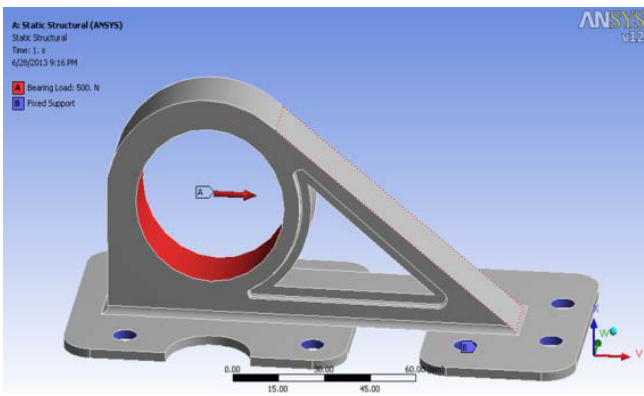

a)

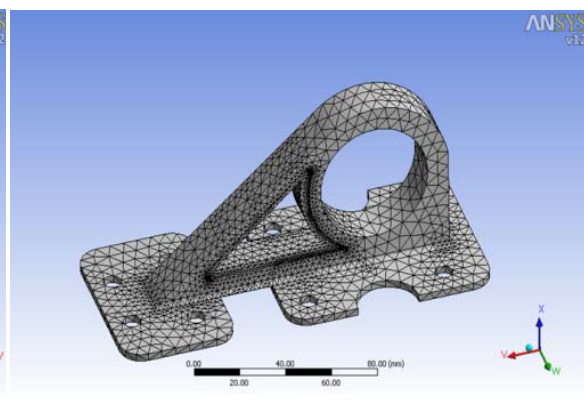

b)

Fig.5. Kinematical, technological constrains and mesh of the analyzed component.

As it was possible to notice by analyzing the equivalent von Mises stresses values that were obtained in the case of AlSil2 and Ti6Al4V materials, the maximum value was $13.122[\mathrm{MPa}]$ in the case of part made of titanium (see Fig. 6.a), as compared to the value of $35.982[\mathrm{MPa}]$ that has been obtained in the case of part made of aluminium (see Fig. 6.b). In both analyzed cases, the maximum stress value resulted in the base plate area of the component (closed to the stressed bore area of $\phi 50 \mathrm{~mm}$ ). Even if the loading force of 500 $[\mathrm{N}]$ was distributed on the entire circumference of the bore, due to the vertical positioning of the component, the action of the gravitational force on the applied force direction determined the apparition of stresses in the area of bores from the base plate that are used for fixing the component on the airplane fuselage. Modifications of the component shape were required to be done in this area in order to minimize the value of the resulted stresses in the structure of the material.

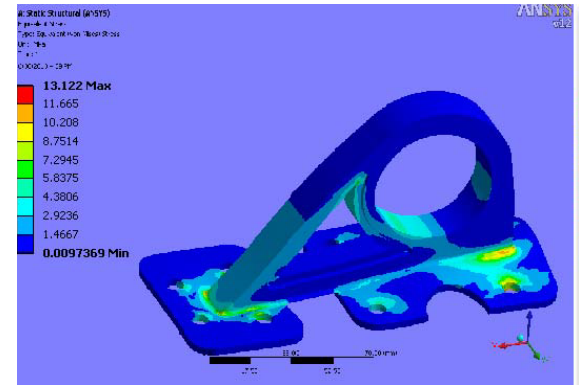

a)

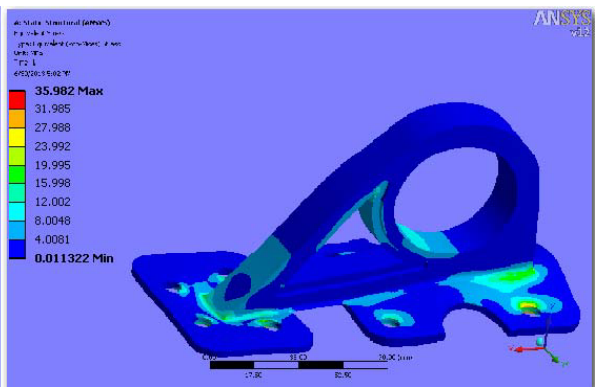

b)

Fig.6. Equivalent stress von Mises, for the component to be made ofTiAl6V4 and AlSi12 material by SLM.

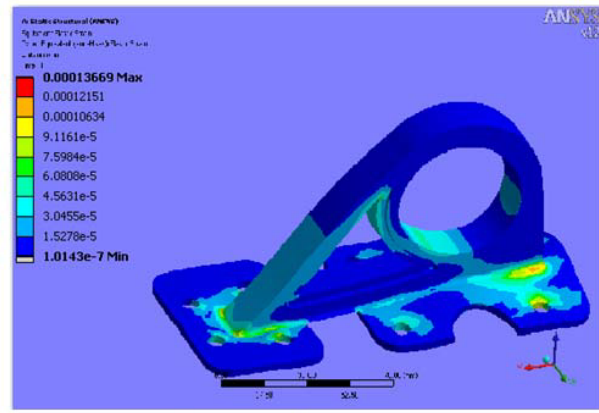

a)

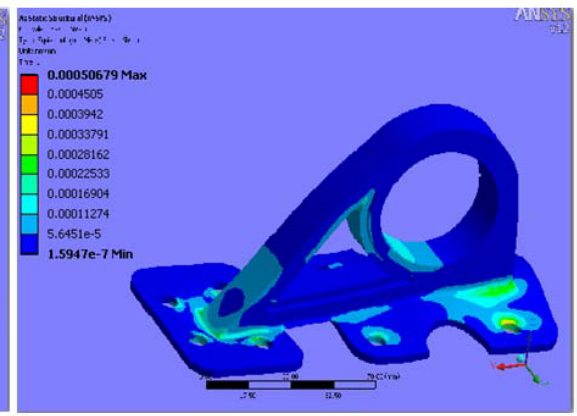

b)

Fig.7. Equivalent strain von Mises, for the component to be made ofTiAl6V4 and AlSi12 material by SLM. 
The equivalent strains von Mises obtained in the case of the component to be made of Ti6Al4V and AlSi12 material by SLM were low, as shown in Fig. 7. a) and b), both in the case of titanium $(0.00013 \mathrm{~mm})$ and aluminium $(0.00056 \mathrm{~mm})$.

Taking into account the preliminary results that were obtained after the finite element analyses that were made by using the ANSYS FEA program and the fact that the stress and strain values were relatively low, both in the case when part has been considered to be made of Ti6Al4V and AlSi12 material, it was possible to redesign the airplane component in order to reduce its weight. The changes that were made at this stage of the analysis in term of reducing the weight of the component were not as significant as it were done using the Femap NX Nastran program, but were possible to be realized without affecting the mechanical behaviour of the component mainly in the area of the base plate in general and in the area of horizontal traverse used for connecting the two sides of the plate, in particular (the stress and strain values were negligible in these areas, in the case of both analyzed materials). As one may notice in Fig. 8.a) and b), the horizontal traverse has been eliminated in the new optimized version of the component that has been designed using SolidWorks.

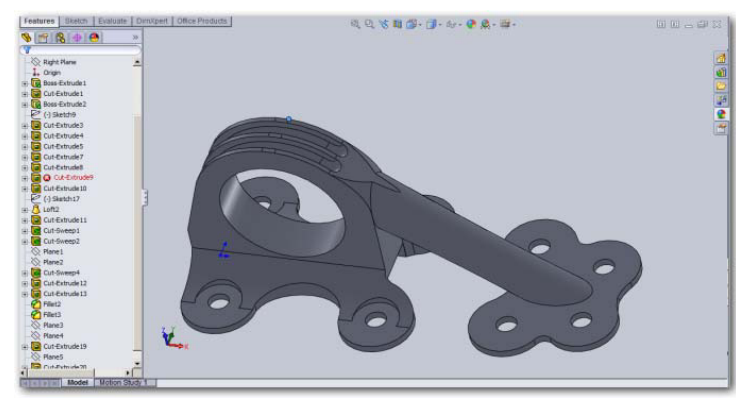

a)

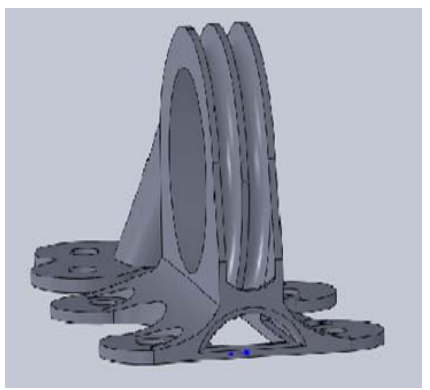

b)

Fig.8. Optimized version of the component designed using SolidWorks.

As shown in Fig. 8. b), there were also realized a series of modifications regarding the external circumference of the $\phi 50[\mathrm{~mm}]$ bore, by realizing a cutting chamfer into the component's wall. The optimized version of the component presented in Fig. 8 represents not only an optimization of the structure of the part, but also an optimization by the technological point of view. The main advantage of the part considered to be made by SLM consists in the fact that the open areas of the part in the wall region of the bore will avoid the cleaning of closed elements from supports in this area, at the end. By realizing all these modifications it was possible to reduce the weight of the component at the end, as well. Of course, in order to validate the final shape of the component, analyses similar to the one described in this chapter was required to be done for the new shape of the component, using the ANSYS FEA program. Not only the shape of the component was considered changed for the made analyses, but also the stressing force in the area of the $\phi 50[\mathrm{~mm}]$ bore, as well. The results that were obtained in the case of optimized shape stressed with different values of forces (from $500[\mathrm{~N}]$ to $3000[\mathrm{~N}]$ ) are briefly presented in Fig. 9. a), b), c) and d).

Taking into consideration the value of the Yield strength which is $815[\mathrm{MPa}]$ in the case of Ti6Al4V material and 211 [MPa] in the case of AlSi12 (see Fig. $4 \mathrm{a}$ and b) and by taking into consideration that the component will be hypothetically stressed with a force higher than $500[\mathrm{~N}]$, considering a safety coefficient of $\mathrm{C}=4$, it was possible to determine by dividing the value of the Yield strength to the value of safety coefficient that $\sigma_{\mathrm{a}}$ would be 203.75 $[\mathrm{MPa}]$ in the case of Ti6Al4V material and $52.75[\mathrm{MPa}]$ in the case of AlSi12. In this case, if the component is stressed with a force value of 1500 [N] the aluminium component will not resist to such a value $\left(\sigma_{\max } \leq \sigma_{\mathrm{a}}\right.$ condition will not be respected in this 
way). This was one of the main reason why Ti6Al4V material has been taken into consideration for manufacturing of the component by selective laser melting technology, being considered as having a properly response by the mechanical behaviour (stress-strain) point of view, taking into consideration the results obtained after the performed analyses realized by using the ANSYS FEA program, as well.

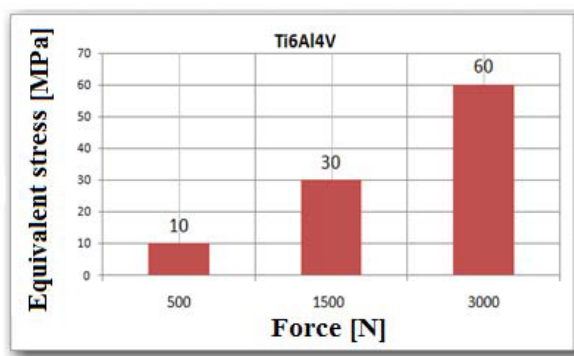

a)

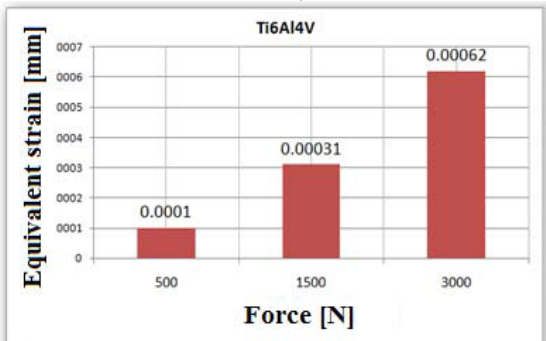

c)

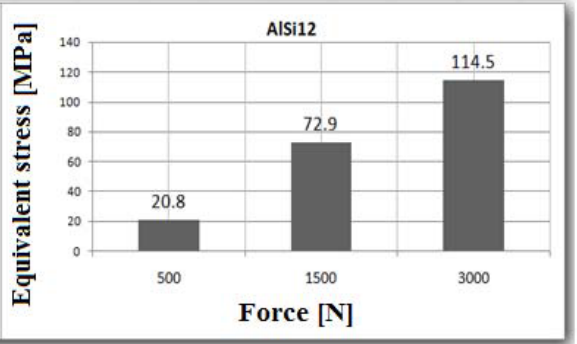

b)

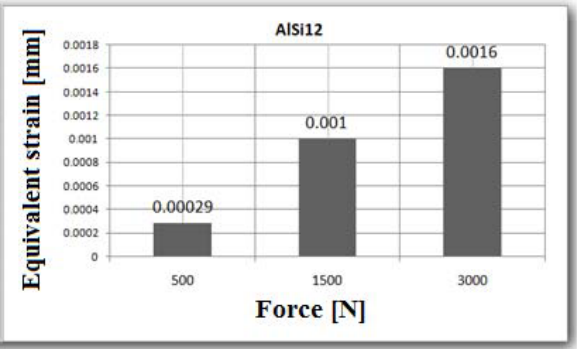

d)

Fig.9. Value of the equivalent stress and strain values for the component with optimized shape.

\section{Manufacturing of the airplane component by SLM technology}

The airplane component was manufactured from Ti6Al4V powder material, using the SLM $250 \mathrm{HL}$ equipment from the SLM Solutions GmbH Company in Luebeck, Germany, presented in Fig. 10. a).

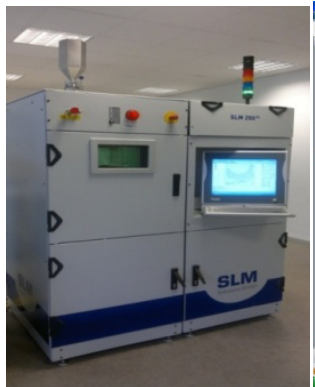

a)

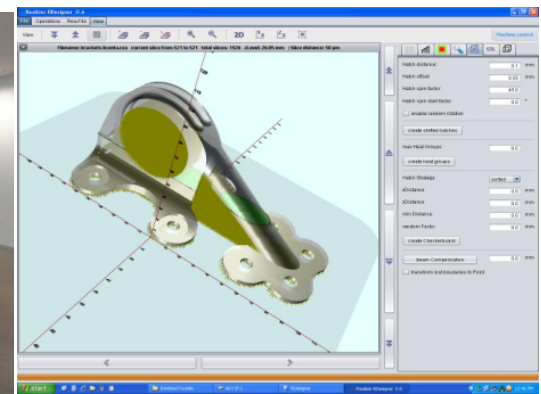

b)

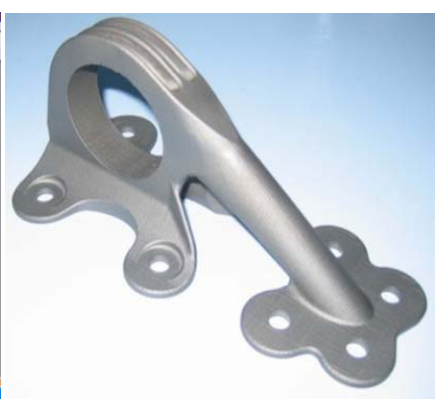

c)

Fig.10. Airplane component manufactured at SLM Solutions GmbH Company from Luebeck, Germany.

Magics software program was used in order to prepare the "*.stl" file and for the support generation to be used for sustaining the part onto the building platform of the machine during the manufacturing process. After the preparation of the "*.stl" file in Magics, the Autofab program was further on used in order to "slice" the model (the 
thickness of one layer was $50[\mu \mathrm{m}], 1526$ layers were obtained in total) and in order to define the technological parameters to be used during the SLM manufacturing process (see Fig. 10. b). A laser power of 175 [W], a scanning speed of $400[\mathrm{~mm} / \mathrm{s}]$ and a powder bed temperature of $180\left[{ }^{\circ} \mathrm{C}\right]$ were used for the realization of solid part, while a value of 100 [W] for the laser power, $250[\mathrm{~mm} / \mathrm{s}]$ for the scanning speed and $200\left[{ }^{\circ} \mathrm{C}\right]$ were used for the realization of the supports. The maximum level of oxygen admissible inside the working chamber of the machine was 0.2 [\%], with a pressure level of the inert gas (argon) having approximately 10 bars. The weight of the component manufactured from Ti6Al4V material by using the SLM 250 HL equipment from SLM GmbH company from Luebeck, Germany had 337.17 grams (see Fig. 10. c).

\section{Conclusions}

Femap NX Nastran program was successfully used for the shape optimization of the fixing clamp component that was used for the sustaining of the hydraulic pipes that are passing through an airplane fuselage, the most important quantity of the material being removed in the connecting area of the base plate and supporting leg of the component. A further shape optimization was required to be done after the finite element analyses that were made using the ANSYS FEA program, in the area of the base plate in general and in the area of horizontal traverse used for connecting the two sides of the plate, in particular. By increasing the value of the stressing force in the bore area of $\phi 50 \mathrm{~mm}$, from 500 [N] to $3000[\mathrm{~N}]$ and by considering a safety coefficient having the value $\mathrm{C}=4$, it was possible to notice that the values of the stress and strain values are too high in the case of aluminium material (AlSi12). This was the main reason why titanium material (Ti6Al4V) has been taken into consideration for the manufacturing of the component by selective laser melting (SLM) technology. The airplane component was manufactured from Ti6Al4V material on the SLM $250 \mathrm{HL}$ equipment at SLM Solutions GmbH company from Luebeck, in Germany, at the end.

This paper was supported by the project entitled "Boosting the scientific excellence and innovation capacity in additive manufacturing of the Technical University of Cluj-Napoca" (AMaTUC), founded by the European Union's Horizon 2020 research and innovation programme under grant agreement No. 691787 (www.amatuc.com).

\section{References}

1. D. Tomus, Y. Tian, P. A. Rometsch, M. Heilmaier, X. Wu, Mater. Sci. \& Eng.: A 667, $42(2016)$

2. Q. Shi, D. Gua, M. Xia, S. Cao, T. Rong, Optics \& Laser Technology 84, 9(2016)

3. B. Zhang, , G. Bi, S. Nai, C. Sun, J. Wei, Optics \& Laser Technology 80, 186 (2016)

4. T. M. Mower, M. J. Long, Mater. Sci. \& Eng.: A 651, 198 (2016)

5. S. Dadbakhsh, B. Vrancken, J.-P. Kruth, J. Luyten, J. V. Humbeeck, Mater. Sci. \& Eng.: A 650, 225(2016)

6. A. Weigang, L. Weiji, Chinese Journal of Aeronautics 20, 524 (2007)

7. D. I. Papadimitriou, C. Papadimitriou, Aero. Sci. \& Tech. 55, 24 (2016)

8. H. Huang, K. Ekici, Aero. Sci. and Tech. 39, 481 (2014)

9. A. M. Gadade, A. Lal, B.N. Singh, Aero. Sci.\& Tech. 55, 227 (2016)

10. SLM Solutions GmbH, SLM Materials Characteristics, 2016, available at: http://slmsolutions.com/sites/default/files/attachment/page/2016/01/151023_slm_metal_powder. pdf, accessed: 10.05 .2016 